\title{
EL AUTORITARISMO DICTATORIAL COMO RELATO CULTURAL. UNA APROXIMACIÓN A LOS MIEDOS SOCIALES EN EL CHILE ACTUAL
}

\author{
Paula Contreras Rojas ${ }^{1}$
}

\section{Resumen / Abstract}

Los relatos culturales dan sentido a la vida cotidiana, a nuestras experiencias y a la forma de entender y explicarnos el mundo en que vivimos. El presente artículo aborda los principales elementos que conforman hoy en día el relato cultural denominado Autoritarismo Dictatorial/Mejor Callar, así como sus implicancias en la configuración de los miedos sociales del Chile actual.

Palabras Clave: miedos sociales, relatos culturales, autoritarismo dictatorial.

THE DICTATORIAL AUTHORITARIANISM AS A CULTURAL NARRATIVE. AN APPROACH TO SOCIAL FEARS IN THE CHILE CURRENT

The cultural narratives give meanings to the everyday life, to our experiences and to the ways of understanding the world we live in. This paper will focus on the main elements that shape the current cultural narrative that we call Dictatorship Authoritarianism / Better Keep Quiet (Hush), and also their implications/effects on the social fears configuration of contemporary Chile.

Keywords: social fears, cultural narratives, dictatorial authoritarianism.

1 Université Libre de Bruxelles. E-mail: paula.contreras.rojas@ulb.ac.be 
El siguiente artículo trata sobre la configuración de los miedos sociales en el Chile actual desde la construcción de relatos culturales que dotan de sentido la vida en sociedad. Para ello, el artículo se centrará en el relato cultural sobre el autoritarismo vivido en la dictadura chilena (1973-1990), destacando los elementos significativos de éste en relación a la configuración de los miedos sociales actuales. Se considera que dicho relato, en conjunto con otros, ha nutrido el proceso de re-significación de los miedos sociales en el Chile actual. Ello, gracias a un contexto donde conviven elementos del pasado régimen autoritario dictatorial junto con nuevos elementos del actual modelo de sociedad.

Como modo de abordar la temática señalada, el artículo se divide en cuatro apartados. El primero presenta de forma breve y concisa una propuesta para introducirse en el estudio de los miedos sociales centrada en el caso chileno, sin descartar su pertinencia para otros casos a investigar. El segundo apartado hace referencia a las principales consideraciones metodológicas de la investigación. El tercero aborda las características del relato cultural sobre el autoritarismo dictatorial desde la relevancia que éstas presentan para la constitución de los miedos sociales actuales. El cuarto y último muestra las principales repercusiones del relato cultural mencionado en relación a los actuales miedos sociales.

\section{Propuesta para abordar el estudio de los miedos sociales}

Las investigaciones relacionadas con los miedos han sido abordadas por autores de diferentes disciplinas. Tema recurrente entre los historiadores franceses ${ }^{2}$, hoy se hace presente en otras áreas de las ciencias sociales ${ }^{3}$.

2 Destacan entre ellos las investigaciones realizadas por: Chauvaud F. (ed.) (2011) L'ennemie intime. La peur: perceptions, expressions, effets. Presses Universitaires de Rennes, Rennes; Delpierre G. (1973), La peur et l'être, Privat; Delumeau J. (Ibíd.); Duby G. (1995), An 1000 an 2000: sur les traces de nos peurs. Textuel, Paris; Febvre L. (1956), "Pour l'histoire d'un sentiment: le besoin de sécurité”. Annales, ESC, n²; Lefebvre G. (1932), La grande peur de 1789. Armand Colin, Paris.

3 Destacan: Reguillo R. (1998), "Imaginarios globales, miedos locales. La construcción social del miedo en la ciudad". Ponencia presentada en el IV Encuentro de la Asociación Latinoamericana de Investigadores de la Comunicación. ALAIC. Recife; Bauman Z. (2007), Miedos líquidos. La sociedad contemporánea y sus temores. Paidós, Barcelona; Robin C. (2009), El miedo. Historia de una idea politica. Fondo de Cultura Económica, Ciudad de México; Marzano M. (2009), Visages de la peur. Presses Universitaires de France, Paris; Bonelli L. (2010), La France a peur. Une histoire socale de linsécurité. La Découverte, Paris; Villa M (ed.). (2002), El Miedo. reflexiones sobre su dimensión social y cultura. Corporación Región, Medellín. 
Problemáticas relacionadas con la comprensión de las relaciones sociales en grandes metrópolis, los traumas y consecuencias derivadas de los regímenes autoritarios, los efectos de la globalización y la modernización, entre otros múltiples escenarios, están siendo abordados desde dicho campo temático. Su desarrollo es incipiente, presenta grandes desafíos tanto en términos teóricos como metodológicos, los cuales son un incentivo y desafío para las actuales investigaciones sobre la temática.

Los miedos pertenecen al mundo de los sentimientos o las emociones (dependiendo del enfoque de cada autor), expresándose a nivel psíquico con repercusiones en nuestra fisiología y en nuestra conducta. Es difícil esbozar el análisis de los miedos, en tanto pertenecientes al mundo de las emociones, sin considerar la dimensión social en la cual se originan y a partir de la cual se les otorga un significado y sentido específico. Para ello, es fundamental aunarlo con un contexto mayor ya sea histórico o en función de ciertos relatos culturales. Ahora bien, también es importante no olvidar que las reacciones en las estructuras psíquicas que ellos desencadenan, se encuentran en relación con las representaciones e imaginarios que cada persona construye de si misma y de su realidad circundante, manifestándose por ejemplo en los procesos de socialización. De hecho, las relaciones sociales y sus prácticas, que son una parte importante de la vida colectiva, pueden verse influenciadas por los miedos sociales. Así, su comprensión implica la relación tanto de lo individualsubjetivo, en cuanto ciertas experiencias nos provocan miedos que a otros no nos llegan a provocar, como de lo colectivo-relacional, en cuanto hay un orden social que genera y distingue que sentimos o concebimos como amenazas.

El siguiente artículo espera ahondar tanto en el mundo de las emociones pero sobre todo en la dimensión social que caracteriza a los miedos. Para ello el caso chileno, especialmente en lo que al autoritarismo dictatorial se refiere, abre una puerta al análisis de los miedos.

Es indudable que la sociedad chilena actual y sus problemáticas sociales están marcada por el modelo que instauró la dictadura en sus 17 años. No obstantelo anterior, también se deben considerar los cambios y re-significaciones implementadas por la pos-dictadura o el periodo de "transición" a la democracia. Sin dejar de lado la importancia de los miedos sociopolíticos dictatoriales, parece ser pertinente plantear que hoy en día los miedos sobrepasan dicha lógica, constituyendo nuevos dominios. Así, concebir los miedos sólo bajo la perspectiva sociopolítica dictatorial no permite comprenderlos a cabalidad, 
pues ellos sobrepasan hoy día el ámbito de la política, situándose en distintas dimensiones de lo social.

Es por elloque creo pertinente para el contexto actual hablardemiedossociales y no sólo de miedos sociopolíticos, considerando que son miedos compartidos por los individuos de una sociedad determinada, en este caso la chilena, que inciden en sus conductas y que responden tanto a relatos culturales (Bajoit, 2008) productores de sentido como a los problemas o conflictos sociales que en ellos se albergan. Son las experiencias vinculadas a los problemas o conflictos sociales, que al ser vividas de forma diferenciada según la posición social de los individuos/sujetos, pueden ser transformadas en productoras de miedos sociales. Ello puede devenir en la formación y persistencia de tensiones socioculturales o de un desasosiego por parte de los individuos en su relación con la sociedad, potenciando procesos de Retraimiento/Parálisis o de Acción/Movilización.

Los miedos sociales, vistos como una mixtura entre los miedos que sembró y utilizó el régimen autoritario dictatorial y los elementos que son propios de una nueva realidad social enmarcada en un modelo neoliberal, se configuran hoy en día a partir de la influencia de tres relatos culturales: El Autoritarismo Dictatorial: Mejor Callar, El Consumo: Tener pero no ser y El Nosotros: Inclusión-Exclusión ${ }^{4}$. Ellos entregan sentido a la vida en común y nos proporcionan las referencias culturales que nos permiten, entre otra cosas, determinar que experiencias pueden ser catalogadas como amenazantes, es decir, productoras de miedos sociales.

Los miedos responden, por tanto, a la relación existente entre la construcción de ciertos relatos culturales (que nos entregan sentido para comprender el mundo en que vivimos), nuestras experiencias sociales diferenciadoras (que dependen de nuestra posición social) y la relación que establecemos con los problemas sociales que nos afectan juntos con la tensión o desasosiego que ellos nos provocan (que intervienen en la forma en que se conforman las experiencias sociales).

Para el estudio de los miedos sociales he considerado ciertos conceptos nodales, en cuanto permiten ahondar en su actual configuración, sus dinámicas y sus dominios. Los conceptos a considerar, y que ya han sido mencionados, son los siguientes: los relatos culturales en cuanto albergan prescripciones

4 En este artículo me centraré en el primer relato cultural, el autoritarismo dictatorial. Si bien, los otros relatos poseen el mismo nivel de importancia, el espacio no permite ahondar y profundizar en sus características. 
normativas y valóricas que delimitan las expectativas sociales, los problemas o conflictos sociales que en cierto modo son parte constituyente de los relatos culturales, las experiencias sociales diferenciadoras que caracterizan la vida cotidiana y se relacionan con la producción de miedos sociales, y las tensiones $o$ desasosiegos socioculturales que son una expresión, entre otras, de los miedos sociales y de cómo se percibe lo social, o la vida en comunidad.

\section{Algunas consideraciones sobre la metodologia}

El siguiente artículo es parte de la investigación doctoral que estoy realizando en el Laboratoire d'Anthropologie des Mondes Contemporains, en la Université Libre de Bruxelles, en relación a los miedos sociales en el Chile actual. Éste tiene como base el trabajo de campo realizado entre diciembre 2012 y junio 2013, como la revisión bibliográfica enfocada en el autoritarismo dictatorial y en los miedos.

Luego de realizar la revisión bibliográfica y considerando la escasa bibliografía y estudios empíricos disponibles sobre la miedos sociales actuales ${ }^{5}$, surgió la pregunta ¿cómo saber qué miedos sociales son los que perciben hoy en día chilenos y chilenas? Es esta pregunta la que introduce la importancia de incorporar esas percepciones actuales a la investigación, para una mayor profundización con base empírica sobre la temática. Así, para ahondar en la percepción actual de los miedos en chilenos y chilenas se realizaron entrevistas en profundidad que permitieron su categorización y caracterización (mapeo). Las entrevistas se concentraron en buscar respuestas principalmente a dos interrogantes ¿Cuáles son hoy en día los principales miedos sociales que los chilenos y chilenas perciben o sienten? Y ¿cómo los chilenos y chilenas ven la sociedad chilena actual?

Para ello se realizaron 24 entrevistas en profundidad en la ciudad de Santiago, además de dos entrevistas de prueba para ver la pertinencia tanto de la pauta como de las temáticas que se esperaban abordar. Las entrevistas contemplaron a mujeres y hombres de entre 30 a 60 años de edad, activos

5 Las investigaciones sobre los miedos en Chile se encuentran generalmente relacionadas a su dimensión sociopolítica y ligados en su mayoría al contexto dictatorial (1973-1990). 
laboralmente, de grupos socioeconómicos medios y bajos, que habitaran en diferentes comunas de Santiago.

Se entrevistó a dos grupos de personas: a) personas con miedos sociales presentes en su vida cotidiana, y b) personas que si bien pueden haber experimentado algún tipo de miedo social en su vida, actualmente no creen que ellos estén presentes en su cotidianidad. De esta forma, las entrevistas mostraron cuáles son los principales miedos sociales, con qué se relacionan, cómo se viven en la cotidianidad, qué prácticas han sido modificadas por la presencia de ellos y la relación entre los miedos pasados y los miedo presentes. También se pudo ahondar en dos discursos o perspectivas de los miedos sociales: la del miedo vivido que interfiere en las prácticas de la vida cotidiana, y la del miedo ajeno, de quien reconoce su existencia en otros pero que su vida cotidiana no se ve afectada por ellos.

Las entrevistas incorporaron, además, un segundo ámbito que tiene relación con las percepciones sobre las características de la sociedad chilena, las principales problemáticas que se cree están presentes en la sociedad y su relación con los miedos sociales. Ello, con la finalidad de ver si existe alguna conexión entre las percepciones de los miedos y el contexto social actual de Chile.

Un tercer y último ámbito en el cuál se enfocaron las entrevista, tiene relación con la dictadura militar (1973-1990) y los miedos sociales actuales. $\mathrm{Al}$ ser éste un tema delicado para algunos personas, se prefirió dejar para el final de la entrevista debido a dos razones: la primera, para que ésta temática no marcara el sesgo de la totalidad de la entrevista; y la segunda, para evitar que sea una imposición por parte de la entrevistada relacionar los miedos sociales actuales con el periodo dictatorial. Cabe destacar que si la temática surgía de forma espontánea ésta se tomaba en consideración y se realizaban las preguntas pertinentes ${ }^{6}$. Será este ámbitos de las entrevistas el que se rescató para la elaboración del presente artículo.

Cabe destacar que en el análisis de las entrevistas se trabajó con estructuras metodológicas de investigación ${ }^{7}$, específicamente con mapas conceptuales de cada una de las entrevistas, como también con mapas que

6 Es importante destacar que si bien muchas veces las personas no nombraban la dictadura militar en la entrevista, al momento de abrir el tema los miedos aparecían como una característica de la dictadura. Considerando las implicancias que el modelo dictatorial tuvo sobre la actual sociedad chilena era un tema que no se podía dejar de preguntar, ya que su omisión podía estar relacionado precisamente con miedos dictatoriales.

7 Arellano (2009). 
agruparan las entrevistas por temáticas y por grupos socioeconómicos. También se trabajó para el análisis con la teoría fundamentada de Strauss ${ }^{8}$ que permitió la codificación analítica de la información proporcionada por las entrevistas.

Relato cultural sobre el Autoritarismo Dictatorial: Mejor Callar, principales elementos que lo caracterizan

La construcción de un relato cultural basado en el autoritarismo dictatorial recoge elementos que fueron característicos de este periodo histórico y que sirvieron para entregar sentido a la vida cotidiana. Los elementos que se destacan han permanecido como parte de la memoria colectiva y, a mi parecer, forman parte de un relato que hoy en día - de forma inconsciente o consciente- influye en las acciones, las expectativas, en la socialización, nutre problemáticas o conflictos sociales y entrega sentido para que ciertas experiencias sean consideradas como productoras de miedos sociales.

Existen algunas características del autoritarismo vivido bajo la dictadura militar (Araujo and Martuccelli, 2012; Araujo and Beyer, 2013; Brunner and Catalán, 1985; Castillo and Lira, 1991; Garretón, 2009; Lechner, 2006c; Pinto and Salazar, 1999), que son importantes de destacar debido tanto a su influencia en la conformación de miedos políticos en dicho periodo, como a las repercusiones que tienen hoy en día en la conformación de miedos sociales. $\mathrm{Al}$ ser un referente importante en la producción de expectativas, normas y valores, dichas características han ayudado a la formación de prescripciones que nos permiten definir y entregar sentido a las referencias culturales para discriminar entre lo que es bueno o malo, deseado o despreciado, justo o injusto, bello o feo, etc. Así, podemos saber cómo actuar, qué decir o pensar, qué temer y hasta qué sentir en diferentes situaciones de la vida cotidiana. Ello es relevante si queremos entender por qué ciertas experiencias son productoras de miedos sociales.

Las siguientes características, si bien, a mi parecer, son las que mejor reflejan la construcción de un relato cultural basado en el autoritarismo del periodo dictatorial, no tienen la intensión de generalizar una época o totalizar e inmovilizar dicho periodo sino, por el contrario, esperan ser un aporte que se enriquezca por otros puntos de vista o reflexiones, considerando que su

8 Corbin, Juliet y Strauss, Anselm. 2002. 
centralidad se encuentra en la construcción y resignificación de los actuales miedos sociales.

a) Sobre el orden/caos y el amigo/enemigo en el autoritarismo dictatorial: "El orden al que uno está acostumbrado, el orden que uno siente es el que te da la tranquilidad"

Una de las características de este relato cultural está relacionada con la consolidación de ciertas dualidades antagónicas que, luego del golpe militar y a lo largo de los años de dictadura, se volvieron parte constituyente de la vida cotidiana y de la práctica de las relaciones sociales. Entre éstas destacan la dualidad antagónica orden/caos y amigo/enemigo, que si bien están relacionadas entre sí, poseen elementos propios que son interesantes de destacar.

En el primer caso, relacionado con la dualidad antagónica orden/caos, es interesante destacar que Chile es un país que posee una estrecha relación con la construcción de un sentido del orden como un valor "ideal”. El qué entendemos por orden (referido a un ámbito más simbólico) y el cómo lo concretizamos (referido a un ámbito más institucional-político o de participación colectiva), al parecer, han marcado la historia de Chile y de sus procesos sociopolíticos ${ }^{10}$. Las características de dicho orden, al cual denominaré orden social pues es transversal a todos los espacios que constituyen la sociedad, ha comprendido tradicionalmente un carácter "nacional”. ¿A qué hace referencia ello y qué implicancias posee?

En primer lugar, el carácter nacional hace referencia a la unidad y la seguridad que el orden social conlleva para toda la población. Lo curioso es que ese carácter nacional, que define qué es lo que entrega unidad, seguridad y por consecuencia tranquilidad, no ha sido una construcción colectiva ${ }^{11}$, sino más bien, se ha construido bajo los preceptos de la élite ${ }^{12}$, dejando excluidos

9 Entrevista a Renato de 34 años.

10 Así lo enfatiza Lechner (2006a) al proponer la reflexión del proceso chileno como una lucha por el orden, especialmente por el orden político, en cuanto lucha por determinar la significación de la política y de la constitución tanto del orden político como de los sujetos políticos. La importancia del orden también es señalada por Pinto y Salazar (1999) quienes plantean que la historia de Chile se ha desarrollado bajo una paradoja histórica entre la sucesión de periodos que destacan por su estabilidad/orden pero que están inmersos en una tensa inestabilidad/caos.

11 Por el contrario, ha existido un extenso temor a la participación y presencia de los sectores más populares en la vida pública, especialmente en la toma de decisiones sobre cómo debe ser la construcción del orden sociopolítico. Ver: Lechner (2006c), Pinto and Salazar (1999), Garretón (2009).

12 Araujo y Beyer subrayan, haciendo referencia a Alberto Edwards, que el orden no es tema que involucre a los sectores populares, éste está en estrecha relación con las élites y las problemáticas 
a amplios sectores de la población. Ello se puede ver ya desde los inicios de la república a partir de dos hechos fundacionales dirigidos por las élites: la institucionalización del orden republicano y la mantención indiscutida del orden heredado (PNUD, 1998). Se mezcla lo nuevo/moderno de las instituciones con lo tradicional/natural del respeto a la autoridad. En este sincretismo el orden social se inscribe en relación a dos ejes principales: una autoridad respetada en cuanto autoridad tradicional, y un gobierno respetado y obedecido en cuanto a su fuerza e inmutabilidad, capaz de estar por encima de los problemas partidistas o personalistas (Araujo and Beyer, 2013). Uno de los principales objetivos de esta autoridad, que ha sido muy bien planteada por Araujo y Beyer (2013) a partir del ideal-tipo portaliano, ha sido velar por la mantención y necesidad del orden que, asociado en este caso a lo nacional, entregaría la unidad y seguridad.

En segundo lugar, el carácter nacional hace referencia a cómo enfrentar el caos que pueden ocasionar los cambios o conflictos al interior de la sociedad. La inestabilidad o inseguridad que pueden producir los cambios o conflictos no han sido construidos como parte del orden, más bien, se ha reforzado la posición de una construcción antagónica- más que de una dualidad complementariaque privilegia ante todo la mantención del orden social vigente sin integrar su reverso: el conflicto o el posible cambio. Para ello, considerando la necesidad y la mantención del orden social como una tarea primordial, el uso de la fuerza ha sido considerado un ejercicio de autoridad legítimo para llevar a cabo dicha tarea. Amparándose en que la subversión del orden social pone en jaque el carácter nacional de unidad y estabilidad, se ha avalado que el ejercicio de la autoridad se produzca a través de la fuerza. Ello ha llevado, en la mayoría de los casos, a respuestas autoritarias y represivas, las cuales han sido aceptadas por parte de la población como un "mal menor" o la necesidad de una "mano dura" que controle la incertidumbre que provocan los problemas o conflictos sociales. Así, se ha privilegiado que el orden debe prevalecer, sin importar cómo, ante un posible caos.

Las implicancias de esta forma de ver y construir la relación orden/ caos, desde un dualismo antagónico, se pueden observar principalmente en el régimen de autoritarismo vivido en la dictadura militar chilena. Es ahí donde se vuelve más tangible la lucha por el restablecimiento del orden (por medio del golpe militar), frente a la desestabilización que produce un supuesto caos (representado por la Unidad Popular y la expansión del "cáncer marxista"13).

que presentan con los gobiernos de turno (Araujo y Beyer, 2013:176).

13 Frase utilizada por el Comandante en Jefe de la Fuerza Aérea de Chile Gustavo Leigh en el primer 
En el régimen de autoritarismo dictatorial la reconfiguración del orden social "nacional" desde los valores conservadores - donde se intentaron enaltecer los valores de la religión católica, consagrando a la familia tradicional como su mayor exponente (Araujo and Martuccelli, 2012)-, intenta reorganizar la vida cotidiana. Se estableció qué generaba estabilidad y qué entregaba seguridad a la población, es decir, cuáles eran los márgenes de acción y pensamiento por los cuales se debía transitar para ser parte del orden social, para estar seguro. Ésto se puede apreciar en el relato de una de las entrevistadas: "Yo nací el sesenta y uno, el setenta y tres tenía doce años, entonces era como criarse cuidando lo que hablabas. Y, o sea, en esa generación mía yo puedo decir que uno se cuida más de hablar, yo no llego y hablo en cualquier lugar. (...) Mejor callar, esa era la opción que nos enseñaron los padres, mejor callar antes que llegar y hablar, sobre todo en temas de política"14.

Todo lo que estuvo fuera de este margen de acción y pensamiento podía ser considerado una amenaza hacia la integridad de la frágil estabilidad (social e individual), especialmente, como señala la entrevistada, todo lo relacionado con temas políticos. Las actividades políticas, la militancia en grupos o partidos de izquierda, las organizaciones poblacionales, los sindicatos, en fin, todo lo que cuestionaba el modelo de orden social instaurado quedó fuera del margen de acción pre-establecido, siendo duramente reprimido. En este escenario no sólo se agudizaron los miedos políticos de los individuos y de la sociedad en su conjunto, sino que se generó una interpretación antagónica de las divisiones sociales creadas por el orden autoritario -como por ejemplo entre terrorista o libertador, entre revolucionario o fascista- que, como bien señala Lechner (2006a: 276) ello desemboca en un solo límite clasificatorio: el de amigo o el de enemigo.

La clasificación amigo/enemigo corresponde al segundo dualismo antagónico que, a mi parecer y en complementariedad con el dualismo ya señalado sobre el orden/caos, es parte constitutiva del relato cultural sobre el autoritarismo dictatorial. Si la mantención del orden social, junto con la lucha contra el caos, se volvió uno de los principales objetivos del régimen autoritario dictatorial, la clasificación amigo/enemigo se convirtió en uno de los medios para que dicho orden social se mantuviera y se naturalizara como el fin último de la vida en sociedad. Es por ello que, al no existir términos medios que incorporen las diferencias, la relación amigo/enemigo se sitúa en un campo de batalla, una guerra del orden contra el caos, donde el enemigo (en este caso el marxismo y sus representantes o adherentes) puede y debe ser eliminado,

discurso televisado de la Junta Militar el 11 de septiembre de 1973.

14 Entrevista a Verónica de 51 años. 
torturado y perseguido en vías de un fin mayor: la seguridad representada por el orden social "nacional". En esta clasificación "el ser de un sujeto depende de que el otro sujeto no sea” (Ibíd.: 275).

En este restablecimiento del orden social, las relaciones sociales fueron permeadas por la clasificación amigo/enemigo, caracterizadas por la incertidumbre de no saber si te encuentras frente a un posible enemigo, o si puedes ser clasificado como tal. Por ello, cómo te comportabas, qué decías, qué callabas o cómo manifestabas tus sentimientos tuvieron que ser muy bien pensados, y hasta cierto punto planificados, para no caer dentro de la clasificación de "enemigo". Así, el espacio público se volvió incierto, inseguro, angustiante e imprevisible, transformando la vida cotidiana, las conductas y la subjetividad de los individuos. Hubo un debilitamiento de la autoconfianza, una agudización de la necesidad de seguridad, una erosión de las entidades colectivas, un apatía y desentusiasmo (Castillo and Lira, 1991; 1993; Lechner, 2006a; b; c; Martín-Baró, 1989; 1990). Todo ello, vinculado al sentimiento de una vida sin sentido y a la pérdida de injerencia en las decisiones colectivas, agudizó el disciplinamiento, tanto delas conductas por medio del autoritarismo, como de los pensamientos por medio de la guerra psicológica ${ }^{15}$. Es en este contexto donde los miedos, especialmente su uso o instrumentalización, jugaron un papel importante en la transformación de la vida cotidiana.

\section{b) Sobre los miedos en el autoritarismo dictatorial: "En la dictadura mucha gente tuvo miedo, la gente hablaba calladita, apagaba la luz temprano"16}

Una segunda característica de este relato cultural está asociada a los usos de los miedos sociales, especialmente los miedos políticos, como propiedad distintiva del régimen de autoritarismo dictatorial. La dualidad antagónica que existe entre orden/caos y amigo/enemigo, profundizada en el contexto de represión y violación sistemática de los derechos humanos, proporcionó las condiciones para sentir que la conservación de la vida se encontraba en

15 La guerra psicológica o acción psicológica está orientada a alcanzar el dominio de la voluntad del otro, alcanzar "la mente" de toda la población con el fin de influir en las conductas y actitudes de los individuos para lograr ciertos objetivos, generalmente políticos. Para una mayor profundización del tema, especialmente en contextos de regímenes autoritarios o dictaduras latinoamericanas, se puede consultar: Castillo and Lira (1991); Lira (1990); Martín-Baro (1989), (1990); Rozitchner (1990).

16 Entrevista a Juan Carlos de 57 años. 
permanente amenaza, asociándola a una constante represión política de carácter arbitrario.

En regímenes autoritarios, el miedo, como bien señala Useche (2008), puede asumir una doble finalidad: puede ser dispositivo de poder a partir de la utilización de la violencia en busca de mantener un orden y generar subordinación entre la población; y puede ser dispositivo de control en cuanto crea la sensación de la omnipresencia del poder y priva de voluntad a las personas. En este período el uso de los miedos se configuró como un elemento de control, el cual provocó una transformación en las vidas cotidianas que intentó moldear lo que se hacía, se quería o se pensaba. Ello se puede observar en dos ámbitos del miedo con predominio de una dimensión política: el miedo como amenaza y el miedo como miedo reflejo.

El miedo como amenaza vital, hace referencia a los peligros presentes en la vida cotidiana del individuo, que pueden afectar ya sea su integridad física ${ }^{17}$ como su integridad material ${ }^{18}$, desestabilizando la conservación y el modo de vida. No siempre nos encontramos frente a una amenaza vital, ella se hace presente cuando los peligros o los sentimientos de inseguridad, que por lo general son parte de la vida cotidiana y son sobrellevados sin grandes alteraciones en ella, se introducen y afectan todos los espacios sociales, conformándose en el centro que determina nuestras conductas y relaciones, o como señala Lechner (Ibíd.) transformándose en peligros mortales ${ }^{19}$. Contar con la certeza o al menos con la probabilidad que la amenaza vital -en este caso relacionada con la represión política- puede ocurrir en cualquier momento, fue capaz de transformar los sentimientos de inseguridad en miedos, desarticulando las rutinas que proporcionaban estabilidad y seguridad.

Lo señalado anteriormente se puede observar en los relatos de algunos de los entrevistados en relación al periodo dictatorial: "Yo soy hija de la dictadura. Nosotros en mi juventud vivimos con muchos miedos. (...) Entonces tenemos muchas vivencias de eso (el miedo en la dictadura). Una vez, yo vivía en San Pablo, con mi hermana estábamos en el balcón que daba a la calle, y vimos como los mataron con metralletas y todo, me entendí?. Entonces uno vio muchas

17 Como pueden ser la tortura, las golpizas, los asaltos, una violación sexual o todo acto que pueda dañarnos físicamente hasta el punto de perder la vida.

18 Como puede ser el desempleo, la pobreza o una crisis económica.

19 Bauman (2007) también plantea la relación del miedo con la amenaza, pero desde otro punto de vista. El miedo sería la ignorancia con respecto a la amenaza y a lo que hay que hacer para combatirla o detenerla. 
$\operatorname{cosas}^{20}$. Otro entrevistado relata: "Yo nací el setenta y cinco, por lo tanto yo nací en dictadura, crecí en dictadura. Yo crecí no con el respeto, con el temor a los carabineros, porque yo vi como baleaban a compañeros, a niños de mi edad. (...) Entonces yo crecí con el miedo, en realidad no con un respeto, con miedo a los carabineros. (...) Hay mucha gente que les pegaron. Mi ex suegro que era secretario de un sindicato, le allanaron la casa, le pegaron. Entonces en realidad no es algo que se inventó, en realidad fue algo que realmente existió, entonces hubo mucho miedo" ${ }^{21}$.

En este contexto, no es difícil de concebir que la amenaza política tenga como respuesta un miedo generalizado en la gente, que puede ser visto tanto como un "miedo crónico" o como una "cultura del miedo"22. Una de sus principales características es que éste ya no es asociado a una amenaza concreta sino que comenzó a ser parte de la vida cotidiana, tanto de las personas afectadas directamente por la represión como de quienes sólo se percibían amenazadas. Al no existir un patrón claro respecto de qué conductas pueden generar situaciones que hagan peligrar la integridad -física o material- se hizo posible la instalación del miedo, al no saber qué conducta anular para estar protegido. Ésto lo expresa muy claramente uno de los entrevistados: "Es lo que hacía la dictadura con los desaparecidos, dentro de los desaparecidos hay gente de muy diversa condición, gente que tenía militancia, que estaba haciendo trabajo y gente que no se tenía idea por qué (desaparecía)" ${ }^{23}$. El miedo, como amenaza vital, se convirtió en parte constitutiva de las conductas como de las relaciones sociales, y se presentó como un elemento de control que potenció la transformación de las inseguridades cotidianas en amenazas vitales, abriendo la puerta a nuevos miedos sociales donde el factor político jugó un rol clave en el qué temer y el por qué temer.

El miedo como miedo reflejo, hace referencia a su construcción y manipulación por los directores de conciencia ${ }^{24}$ de la colectividad y su capacidad de dirigir desgracias, manipular miedos ya presentes en la población o crear miedos con un fin específico (Delumeau, 2008). Ejemplo de ello fue la

20 Entrevista a Karla de 45 años.

21 Entrevista a Roberto de 37 años.

22 El primer término es utilizado por Castillo y Lira para el caso de autoritarismo en Chile, mientras que el segundo es utilizado por O’Donnell al referirse al caso de autoritarismo en Argentina.

23 Entrevista a Rodolfo de 57 años.

24 Delumeau se refiere específicamente a los hombres de Iglesia en Europa, pero pueden encontrarse otros ejemplos para Latinoamérica como son las misiones evangelizadoras en la conquista española, las élites criollas en la época independentista o los diversos caudillismo del siglo XIX junto con las dictaduras que azotaron la región entre las décadas de los 50’ y 70’ del siglo XX. 
denominada "campaña del terror", como relata uno de los entrevistados: "En el año sesenta y cuatro, cuando fue la campaña presidencial estaba Allende, antes de que ganara en el setenta, hubo una cosa que se denominó la campaña del terror y se asociaba a que si llegaba Allende les iban a quitar a los hijos, los iban ha... y todo un montón de cosas terribles que iban a suceder si ganaba Allende como presidente. Y pasó lo mismo después en el año setenta, todo se instaló en función del miedo, es decir, lo que viene es horrible"25

En el caso del régimen dictatorial chileno, el miedo reflejo no sólo se nutrió de la amenaza vital que generó la represión por medio de la coacción, sino que también se alimentó de los miedos que los grupos dominantes o dirigentes sintieron ante el posible cambio del orden social imperante, impulsado por la Unidad Popular. La potencial perdida de los beneficios o privilegios se pudo traducir en la sensación de una amenaza vital, respondiendo ante ella con miedo e intentando mantener, ya sea con el uso de la fuerza o por medio de una violencia simbólica, sus visiones del mundo, de la sociedad y de cómo ésta debe organizarse (Delumeau, 1993; Gómez, 2010; Useche, 2008). Para ello, se ocuparon principalmente los medios masivos de comunicación de masas como forma de influir en el disciplinamiento de los pensamientos y de las conductas. Se buscaba con estas acciones la despolitización de la población, la erosión de las entidades colectivas (Lechner, Ibíd.) y la instauración de un nuevo orden social con una clara orientación neoliberal ${ }^{26}$.

No fue sólo por medio de la manipulación de los medios de comunicación que el miedo reflejo actúo como elemento de control, también se desplegaron prácticas que por su gran carga simbólica ayudaron a dicho control. Ello se puede percibir muy bien en el relato que uno de los entrevistados hace sobre su experiencia en dictadura: "Yo me acuerdo que en el colegio, en historia, no nos pasaban el golpe de Estado, no nos pasaban el gobierno de Salvador Allende, nos enseñaban marchas, en todo el colegio, de la armada, de los militares, el himno nacional todos los lunes. Hoy día creo que no se hace eso, con la bandera. Entonces era todo un contexto militarizado. Yo veía, estaba justo en

25 Entrevista a Rodolfo de 57 años.

26 Ejemplo de ello fue la manipulación de titulares, como el publicado por el diario La Segunda - de tendencia oficialista- el 24 de junio de 1985, en el cual se leía: "Exterminados como ratones: 59 miristas chilenos caen en operativo militar en Argentina”. Publicación que tenía el fin de justificar el asesinato de 119 personas vinculadas al Movimiento de Izquierda Revolucionaria (MIR), y que posteriormente fue conocido como la Operación Colombo, que intentó dar a conocer al público -en complicidad con diarios argentinos y brasileños- que los miristas se mataban entre ellos, descartando la participación del gobierno dictatorial en sus muertes y desapariciones. 
la Alameda, pasaban tanquetas por la alameda, guanacos, entonces imagínate estar en quinto básico ver eso es temor, no te causa otra cosa”.

Tanto los miedos como amenaza o como miedos reflejos pueden ser vistos como un ejemplo de cómo se utilizó e intensificó el discurso amigo/enemigo en donde significantes como el comunismo, el marxismo o la izquierda fueron apropiados y resignificados por el autoritarismo bajo la forma de miedo al caos y a la inestabilidad social. La militarización de la vida cotidiana, el despliegue del aparataje militar, la instauración de "una" historia oficial, los ritos en los colegios, entre otras prácticas, son elementos que ayudaron a generar un contexto de temor y amenaza hacia lo que se alejaba del margen de acción instaurado por el autoritarismo dictatorial. La negación de la diferencia y de la tolerancia, junto con la construcción mediática del otro/enemigo como terrorista, subversivo o violentistas, acentuó el miedo hacia quienes pensaban diferente identificándolos como una amenaza a la estabilidad que proporcionaba el orden y creando estereotipos o categorizaciones de las personas.

\section{c) Sobre los estereotipos en el autoritarismo dictatorial: "Yo recuerdo que en mi juventud (dictadura) era terrible pensar quées lo que va a decir la gente"}

Una tercera característica de este relato tiene relación con la creación de diversos estereotipos como forma de referirse a quienes no son parte de un grupo específico o no calzan dentro del orden social deseado por el régimen dominante. Éstos se construyen a partir de una diferenciación que distingue quién pertenece a un "nosotros" y quienes están fuera de esta construcción, es decir, quienes serán representantes de la otredad, en la construcción de un "otro". Los estereotipos, según Niño (2002), resaltan características y clasificaciones que no se tienen o no se quieren tener, conformando prejuicios que se generalizan y permiten una identificación del otro en el contexto social. El estereotipo, que se basa en la diferenciación social, expresa un tipo de dominación, de jerarquía social y de distribuciones de poder diferenciadas. Crea relatos y rumores desde la esfera dominante, los que se entrecruzan con la resignificación que se hace de ellos desde los grupos dominados y desde los mismos grupos que están siendo estereotipados. De esta forma, los relatos y rumores asumen nuevas formas y sentidos.

Es importante considerar que la conformación de estereotipos tiene componentes de la realidad pero, como señala Niño (Ibíd.), también tiene componentes de la fantasía. Ambos logran reforzar ciertos imaginarios

27 Entrevista a Karla de 45 años. 
sociales por medio de relaciones de poder, dirigidas a manipular y contribuir a la mantención de una posición, situación o actitud. Los estereotipos son, para la autora, una forma de control social dentro de un sistema determinado, que relacionan a ciertas personas o grupos con la producción de miedos: "son miedos que nos hacen sospechar del vecino, ver en el otro un peligro potencial, aspectos que bloquean lazos de solidaridad, nos aíslan y nos encierran, haciéndonos evadir al otro, evitar el encuentro, y sentirnos en una ciudad de todos pero a la vez de nadie" (Ibíd.: 203). Los estereotipos asociados al autoritarismo, y a los miedos que este periodo consolidó, pueden ser vistos desde dos ámbitos.

En primer lugar, se puede distinguir el estereotipo como un elemento que fomentó la construcción de un otro desde una perspectiva político-negativa. En el proceso de autoritarismo dictatorial chileno, la construcción de estereotipos en relación a experiencias productoras de miedos -especialmente políticas- se encontró claramente asociada a las dos dualidades antagónicas (orden/caos, amigo/enemigo) ya mencionados. En dicho proceso se fomentaron estereotipos que, en privilegio de la visión amigo/enemigo, ayudaban a distinguir entre quienes estaban a favor o en contra del "orden social". Es decir, a favor de las nuevas prescripciones normativas y del nuevo modelo político y económico que la dictadura estaba implementando -por ejemplo el restablecimiento de los valores tradicionales o un modelo de país centrado ya no en el Estado sino en el mercado- ${ }^{28}$, o en contra de dicho orden social, asumiendo que ello implicaba avalar un estado de "caos".

Un ejemplo de ello es el relato de uno de los entrevistados que rememora un interrogatorio en la puerta de su casa realizado por carabineros: "usted conoce a una persona que se llama Yamna?; Si, claro; Ah! Usted reconoce que la conoce!; Si, pero por supuesto que la conozco, ella es amiga, nosotros hemos vivido aqui treinta años! les dije: La conozco desde que teniamos cerca de 10015 años; Entonces, ¿Usted no sabe que ella es extremista?; No, que va a ser extremista la Yamna; ¿Usted no la ha visto nunca con armas?, y les dije: Mire, sabe qué, no, esa no es la Yamna que yo conozco, a lo mejor es alcance de nombre; y me mostró la foto, Sí, esa es la Yamna, pero no es como usted me dice, yo la conozco deotramanera" ${ }^{29}$. En este relato es posible observar cómo el "otro" se construye a partir de características estereotipadas que resaltan sólo una pertenencia identitaria desde una construcción negativa, en este caso la participación política asociada al estereotipo de "extremista". Pero también, la construcción del estereotipo, en este caso el de "extremista", se nutre de rumores creados por los grupos dominantes que a su vez son

28 Para una mayor profundización en el tema consultar Araujo y Martuccelli (2012).

29 Entrevista a Gerardo de 59 años. 
alimentados por la cultura popular. El rumor del "comunista come guagua", muchas veces asociado e identificado con el estereotipo de "extremista", o con el ya mencionado "cáncer marxista”, es un ejemplo de ello.

La conformación de estereotipos que fomentaban un nosotros/otros y un amigo/enemigo volvió rígidas y estrechas las capacidades para desenvolverse en el cotidiano, construyendo relaciones interpersonales basadas en los estereotipos desde una resignificación negativa de la pertenencia. Así lo plantea Martín-Baró (1989), quien analiza el caso de autoritarismo en El Salvador, al señalar que existe un debilitamiento de la autoestima y de la confianza del individuo relacionado con la búsqueda continua de las claves y orientaciones para ser clasificado en público. Si bien el caso que el autor analiza no es el chileno, en él se pueden encontrar ciertos elementos del autoritarismo, como los señalados, que traspasan las fronteras territoriales o nacionales.

En segundo lugar, se puede distinguir que los estereotipos en función de la construcción de un otro estaban influidos por la formación de etiquetas, las cuales encasillaban y limitaban la construcción identitaria, enarbolando sólo una de las múltiples pertenencias que componen la identidad de un individuo. Dicha situación puede devenir rápidamente en problemas identitarios, que como bien señala Maalouf (2008), puede llevar a fortalecer identidades asesinas en torno a la identificación de una colectividad o un grupo de personas con una sola pertenencia y no con la multiplicidad de pertenencias que conforman las identidades. Muy bien lo señala uno de los entrevistados, quien afirma que: "En la época de la dictadura el otro era todo aquel que se oponía a la dictadura, que era extremista, terrorista, subversivo, etcétera, tenía una etiqueta" ${ }^{30}$. La persona era categorizada dentro de un esquema cerrado que donaba prescripciones morales y valóricas, positivas o negativas, a la etiqueta en cuestión. Dependiendo de dicho esquema se realizaba la práctica de las relaciones sociales, eras merecedor o no de confianza, de estima o de la simpatía de las otras personas, teniendo como consecuencia relaciones sociales mediadas por los estereotipos adoptados (Martín-Baró, 1989).

Así lo expresa una de las entrevistadas al referirse al tema: "Yo creo que sí hubo un miedo a ser estigmatizada en dictadura, porque si eras de un determinado partido político, y fuiste detenida política, y pasaste varios meses en la cárcel, quedabas como etiquetada (...) Había que portarse bien, había que "portarse bien" entre comillas, y eso era no militar, porque si te portabas

30 Entrevista a Rodolfo de 57 años. 
mal eras como la oveja negra y quedabas como clasificada" ${ }^{31}$. Las etiquetas que forjaron los estereotipos en dictadura estuvieron asociados, por lo general, a elementos de la vida política que podían implicar una posible represión que amenazara la integridad física: el soplón, el extremista, el comunista, el fascista, entre otras, fueron etiquetas que crearon estigmas que impedían la aceptación social (Goffman, 2006). Ello podría haber llevado en muchos casos a generar temor entre la población y, junto con otros elementos, haber sido uno de los detonante de la despolitización de la vida social, la desmovilización y la baja participación, fomentando el alejamiento de la política en la vida cotidiana.

Repercusiones del relato sobre el autoritarismo-dictatorial en la conformación de miedos sociales actuales.

Como ya se mencionó, los relatos culturales nos ayudan a interpretar y entregar sentido a la vida cotidiana, a nuestras relaciones sociales y a nuestras conductas. Son, en cierta manera, las explicaciones que creamos sobre la vida en sociedad y las justificaciones que damos a ella. Así mismo, proporcionan elementos que nos permiten configurar y situar nuestras expectativas según las prescripciones normativas que caracterizan a cada época histórica.

Para comprender los miedos sociales en el Chile actual me parece importante ahondar en los principales relatos que hoy en día influyen en cómo nos explicamos la vida en sociedad. Particularmente, pensar qué elementos de esos relatos están en relación con nuestros actuales malestares sociales, con los problemas o conflictos que como sociedad enfrentamos y, sobre todo, en relación con la configuración de experiencias sociales diferenciadoras en cuanto productoras de miedos sociales.

Considerando las particularidades históricas de Chile cabe preguntarse ¿cómo repercute el relato cultural asociado al Autoritarismo Dictatorial en la actual configuración de los miedos sociales? Creo que el periodo de dictadura entrega elementos que hoy en día son importantes de considerar en la configuración de los miedos sociales, pero es preciso recalcar que no es "el único determinante" de éstos. Hoy en día es necesario considerar los elementos culturales, económicos, políticos y sociales propios del periodo post-dictatorial y que también contribuyen a la formación de los actuales miedos sociales. Si

31 Entrevista a Verónica de 51 años. 
bien no ahondaré en dichos elementos me parece prudente enfatizar en ello para evitar malos entendidos.

Para intentar responder la pregunta formulada en el párrafo anterior, y como forma de acercarse a dicha interrogante, abordaré a grandes rasgos y a modo de una aproximación analítica inicial, los principales puntos en los cuales el relato cultural del Autoritarismo Dictatorial ha presentado una influencia significativa en la actual conformación de los miedos sociales. Para ello plantearé las repercusiones desde las principales características de los relatos culturales señaladas con anterioridad.

\section{a) El relato cultural dota de sentido a la vida en sociedad. Repercusiones en la construcción de un "otro" desde una valoración negativa}

En el contexto de autoritarismo dictatorial que vivió Chile, donde la dualidad antagónica orden/caos acentuó la construcción de visiones de la sociedad clasificadas entre amigos/enemigos, la amenaza se caracterizó por ser de carácter político, especialmente en contra de quienes se identificaban con el proyecto político de la Unidad Popular o con un cambio social. La represión masiva que se vivió en dictadura y los distintos modos de ejercerla ${ }^{32}$, no estuvieron sólo dirigidos a quienes se encontraban en una posición política contraria a la dictadura militar, sus efectos en cuanto "acción psicológica" permearon todos los grupos sociales generando la sensación de indefensión y de potencial victima.

El uso del miedo jugó un papel importante en ello. Como bien señala Lechner (Ibíd.), el autoritarismo realiza una apropiación de los miedos ya existentes ideologizándolos, resignificándolos y borrando las referencias a las amenazas reales. Si bien la violencia represiva que ejercía la dictadura pudo ser vista como la amenaza real, ésta fue resignificada y centrada en un "otro", ya sea el terrorista, el delincuente o el extremista de izquierda, que atentaba contra el orden social -dictatorial- que se intentaba resguardar y reconstruir.

32 Entre algunos de estos modos de ejercer la represión se encuentran las torturas, los secuestros, los asesinatos, las desapariciones, los allanamientos, las persecuciones, los despidos, los hostigamientos, la guerra psicológica, la desarticulación de las organizaciones políticas y sociales, la propaganda en medios de comunicación y la intervención ideológica en establecimientos educacionales, por mencional algunos. 
Para ello el uso de los miedos reflejos fue de gran ayuda y una forma sigilosa de intervenir y controlar voluntades y pensamientos.

Sin necesidad de la fuerza represiva de las armas, los miedos penetraron las mentes de las personas y se instalaron en ellas. Cuando la sociedad interioriza estos nuevos miedos, procesados por el poder, logra transformar las rutinas y volver imprevisible la vida colectiva. Desaparece la normalidad y el entorno más próximo se vuelve ajeno y hostil provocando un sentimiento generalizado de impotencia, pues consiente o inconscientemente se percibe que ya no se puede injerir en la construcción de las condiciones de vida. Ello implica a largo plazo una apatía, un desentusiasmo y descompromiso frente a un mundo en el que no puedes injerir, en el que el arraigo social se desvanece (Castillo and Lira, 1991; Lechner, 2006b; Martín-Baró, 1989).

En este proceso las relaciones sociales están marcadas por la desconfianza, la vida singular se repliega a su inmediatez y no permite crear horizontes de futuro o imaginarios colectivos donde la vida común pueda ser concebida y abordada como obra de todos. El miedo reflejo, asociado al autoritarismo, puso énfasis en la penetración de una nueva forma de habitar lo social donde la diferencia de pensamiento o de actuar fue vista desde su negatividad y no desde su riqueza como aporte a la vida en sociedad. Ejemplo de ello son la construcción de estereotipos frente a situaciones relacionadas a la vida política.

Hoy día el miedo no se centra especialmente en el ámbito de la política, pero ciertos miedos actuales tienen parte importante de sus raíces en el periodo de autoritarismo dictatorial y en relación con la construcción del "otro". Lo podemos ver en el miedo al otro, ejemplificado en la difícil tarea de aceptar las diferencias y las diversas pertenencias identitarias que caracterizan a los individuos, o en el miedo a la gente, centrado en la desconfianza que genera la relación con el prójimo.

Sin ser el único elemento relevante en la construcción del "otro" desde la negatividad, el relato cultural asociado al Autoritarismo Dictatorial entrega elementos para su comprensión y contextualización. Elementos como la poca injerencia en la vida colectica o la sensación de potencial victima replegaron la vida cotidiana y la sociabilidad hacia una esfera más privada que pública. La construcción tanto del espacio público como de la vida cotidiana fue alejada de una visión de colectividad integradora de las diferencias y centrada en los elementos negativos de ésta. En este proceso la visión de orden/caos, 
amigo/enemigo, los miedos reflejos y la creación de estereotipos ayudaron a la conformación de un "otro" que interpela sólo la negatividad de las pertenencias identitarias.

b) El relato cultural alberga ciertos problemas o conflictos sociales no resueltos. Repercusiones en la tensión o desasosiego sociocultural

El relato cultural sobre el Autoritarismo Dictatorial pone de relieve ciertos elementos que están hoy en día conectados con dicho proceso histórico caracterizándolo y mostrando su relación con la conformación de miedos sociales pasados ${ }^{33}$ que, de alguna forma, se mantienen latentes en la actualidad (matizados y resignificados por el contexto socioeconómico presente) a través de problemáticas y conflictos sociales que son causas de tensiones o desasosiegos entre los individuos.

El cambio que implicó pasar de un modelo centrado en el Estado desarrollista a un modelo donde predomina la autonomía del mercado, mediado por una dictadura fuertemente represiva, marca las actuales problemáticas y conflictos que debemos enfrentar como sociedad. También marca y entrega sentido a los relatos sobre el Consumo/Tener pero no ser y sobre el Nosotros/ Inclusión-Exclusión que acompañan el relato cultural sobre el Autoritarismo Dictatorial/Mejor callar y que permiten un posible acercamiento hacia la actual configuración de los miedos sociales.

El relato cultural sobre el Autoritarismo Dictatorial aloja actualmente ciertos conflictos o problemáticas que no han sido resueltas en este proceso de cambio de modelo. Temas como la violación a los derechos humanos o el tipo de orden social en el cual convivimos se presentan, metafóricamente hablando, como el centro de una gran telaraña en donde se van uniendo e hilando diferentes problemas y descontentos. No es menor que el dualismo antagónico orden/caos y amigo/enemigo hayan ayudado a consolidar una forma de enfrentar la construcción de lo que el orden social implica (normativa, práctica y simbólicamente), privilegiándose la visión o deseo de la autoridad por sobre la visión o deseo colectivo. O que las torturas, asesinatos o desapariciones no presenten culpables claros y precisos, donde el repudio de dichos actos

33 Sin la intención de caer en la reiteración, es bueno destacar que los miedos sociales actuales también están nutridos de elementos que ya no están en una estrecha ilación con el proceso de autoritarismo dictatorial, aunque en este artículo no se profundice en ello es importante destacarlo. 
conformen parte de la memoria histórica oficial. Ello por mencionar sólo dos ejemplificaciones de los hilos de la mencionada "tela de araña".

¿Pero qué sucede con estos problemas que se pueden rastrear en el relato cultural del Autoritarismo Dictatorial y qué relación presentan con los miedos actuales? En primer lugar dichos problemas, junto con otros de igual importancia (las crecientes desigualdades socioeconómicas, por ejemplo), son una forma de ahondar en cómo vivimos las experiencias y hasta que punto algunas pueden ser productoras de ciertos miedos sociales. El actual miedo a la autoridad o el miedo al conflicto no tendrán la misma relevancia para quienes vivieron experiencias marcadas por la represión política o por el apoyo al actuar militar. No implica que el miedo no exista en ambos tipos de personas, pero éste tendrá características diferentes dependiendo de cómo vivimos y enfrentamos las experiencias y de las herramientas que tengamos en nuestra vida cotidiana para enfrentar dichos miedos. Los problemas o conflictos sociales pueden ser un camino para ahondar en las experiencias sociales en cuanto diferenciadoras y su relación con la producción de miedos sociales.

En segundo lugar, los problemas sociales son también una forma de ahondar en las tensiones o desasosiegos sociales. Dentro de las diversas tensiones que los entrevistados mencionaron, me parece relevante destacar dos de ellas que presentan una marcada cercanía con los elementos del relato cultural sobre el Autoritarismo Dictatorial ya mencionados. Estos son la desconfianza y el individualismo. Ambos se presentan como un desasosiego que genera el vivir en una ciudad como Santiago, y se relacionan con un pasado dictatorial que ha consolidado cierta forma de habitar lo social, con valores, expectativas y estereotipos basados, en su mayoría, en un modelo donde predomina la autonomía del mercado. En este ámbito cabe preguntarse si los malestares pueden potenciar procesos de Retraimiento/Parálisis o de Acción/ Movilización.

c) El relato cultural permite determinar que experiencias sociales son amenazantes. Repercusiones en las expresiones colectivas.

Durante el periodo de autoritarismo dictatorial las personas intentaron reducir las posibles amenazas que pusieran en peligro la integridad física o la integridad material. Las inseguridades cotidianas de la vida diaria, que son parte constituyente de vivir en sociedad, se transformaron rápidamente en amenazas vitales, es decir, en miedos sociales muchas veces de carácter colectivo. La ambigüedad del origen de la amenaza como la sensación de indefensión que 
ello provocaba, fomentó la estructuración y rigidez de las prácticas sociales, identificando qué, cómo, cuándo y dónde hablar y actuar.

Ciertas prácticas fueron asociadas con la mantención del orden social y otras con la provocación del caos. Quienes estaban en el primer grupo formaron parte de lo que hemos denominado amigos y los del segundo grupo formaron parte de la denominación enemigo (siempre visto desde quienes ejercían el poder, es decir, desde el régimen de autoritarismo dictatorial). El miedo reflejo estereotipó e infundió temor a partir de este dualismo antagónico. Así, toda práctica que estuviera en contra de la dictadura expresadas por ejemplo en manifestaciones públicas (mítines, marchas, barricadas, performance, etc.), militancia política, organización sindical, comunicación de la violación a los derechos humanos fue considerada caótica y parte de la construcción estereotipada del "otro" desde la negatividad.

No es de extrañar entonces que las experiencias sociales asociadas a las prácticas mencionadas fueran consideradas como parte de una potencial amenaza vital y fueran origen de miedos sociales, especialmente de miedos políticos. Hoy en día, especialmente en los grupos etarios que vivieron su adultez, juventud o niñez en plena dictadura, se pueden observar ciertos miedos asociados a las experiencias que fueron consideradas amenazantes en dicho periodo. Ello se puede ver especialmente en el miedo a la expresión colectiva, asociado al caos que una manifestación pública puede desatar, al actuar de carabineros en ella y a los efectos que puede dejar la multitud descontrolada. Cabe considerar que dicho miedo no implica a priori el retraimiento o parálisis en el individuo, la acción o movilización pueden estar presentes sin descartar que por ello el miedo señalado también lo esté.

Es en esta condición hibrida donde ciertos miedos se sitúan en la actualidad, entre los vestigios que dejó el periodo de autoritarismo dictatorial, el sincretismo que ofrece pasar de un modelo centrado en el Estado a un modelo neoliberal de mercado, y las nuevas características culturales, políticas, sociales y económicas que dejaron de tener su centro en el autoritarismo dictatorial. En este nuevo contexto, preguntarse por las experiencias sociales amenazantes como productoras de miedos sociales es una forma de abordar la actual configuración de dichos miedos. 
Referencias bibliográficas.

Araujo, Kathya, and Danilo Martuccelli (2012). Desafíos comunes. Retratos de la sociedad chilena y sus individuos, Tomo I, LOM Ediciones, Santiago.

Araujo, Kathya, and Nelson Beyer, "Autoridad y autoritarismo en Chile. Reflexiones en torno al ideal-tipo portaliano", Atenea, No 508, (2013). 171 - 185.

Arellano (2009). José; Santoyo, Margarita, Investigar con mapas conceptuales: procesos metodológicos. Ediciones Narcea, España.

Bajoit, Guy (2008). El cambio social. Análisis sociológico del cambio social y cultural en las sociedades contemporáneas, Siglo XXI, Madrid.

Bauman, Zygmunt (2007). Miedos Líquidos. La sociedad contemporánea y sus temores, Paidos, Barcelona.

Brunner, José Joaquín, and Gonzalo Catalán (1985). Cinco ensayos sobre cultura y sociedad, FLACSO, Santiago.

Castillo, María Isabel, and Elizabeth Lira (1991). Psicología de la amenaza política y del miedo, Ediciones ChileAmerica CESOC, Santiago.

Castillo, María Isabel, and Elizabeth Lira, "Trauma político y memoria social”, Psicología Politica, No 6, (1993). 95-116.

Corbin, Juliet y Strauss, Anselm (2002). Bases dela investigación cualitativa. Técnicas y procedimientos para desarrollar la Teoría Fundamentada. Universidad de Antioquia, Medellín.

Delumeau, Jean, “La peur et l'historien”, Communications, No 57, (1993). 17-23.

Delumeau, Jean (2008). El miedo en occidente, Taurus, Ciudad de México.

Garretón, Manuel Antonio, "Problemas heredados y nuevos problemas en la democracia chilena. ¿Hacia un nuevo ciclo?”, in Economía, Instituciones y Politica en Chile, edited by Gloria de la Fuente, Sergio Contreras, Paulo Hidalgo and Julio Sau, (2009). División de Estudios Ministerio Secretaría General de la Presidencia, LOM Ediciones, Santiago. 
Goffman, Erving (2006). Estigma. La identidad deteriorada, Amorrortu Buenos Aires.

Gómez, Juan Carlos, "Violencia, terror y miedo político en la sociedad neoliberal chilena", El Chileno, http://elchileno.cl/comentarios/493violencia-terror-y-miedo-politico-en-la-sociedad-neoliberal-chilena.html, (2010).

Lechner, Norbert, "La conflictiva y nunca acabada construcción del orden deseado", in Norbert Lechner. Obras escogidas 1, edited, (2006a). LOM Ediciones, Santiago.

Lechner, Norbert, "Los patios internos de la democracia", in Norbert Lechner. Obras escogidas 1, edited, (2006b). LOM Ediciones, Santiago.

Lechner, Norbert (2006c). Obras Escogidas 1, LOM Ediciones, Santiago.

Lira, Elizabeth, "Guerra psicológica: intervención política de la subjetividad colectiva", in Psicología social de la guerra: trauma y terapia, edited by Ignacio Martín-Baró, (1990). UCA Editores, San Salvador.

Maalouf, Amin (2008). Identidades Asesinas, Alianza Editorial, Madrid.

Martín-Baró, Ignacio, "Las consecuencias psicológicas del terrorismo político", Simposio sobre las consecuencias psicológicas del terrorismo político, (1989).

Martín-Baró, Ignacio (1990), Psicología social de la guerra: trauma y terapia, UCA Editores, San Salvador.

Niño, Soledad, "Ecos del miedo en Santafé de Bogotá e imaginarios de sus ciudadanos", in El miedo. Reflexiones sobre su dimensión social y cultural, edited by María Inés Villa Martínez, (2002). Corporación Región, Medellín.

Pinto, Julio, and Gabriel Salazar (1999). Historia contemporánea de Chile. Estado, legitimidad, ciudadanía, Vol. I, LOM Ediciones, Santiago.

PNUD, Programa de las Naciones Unidas para el Desarrollo (1998). Las 
paradojas de la modernización, Santiago.

Rozitchner, León, "Efectos psicológicos de la represión", in Psicología social de la guerra: trauma y terapia, edited by Ignacio Martín-Baró, (1990). UCA Editores, San Salvador.

Useche, Óscar, "Miedo, seguridad y resistencia: el mido como articulación política de la negatividad", Polis, Revista de la Universidad Bolivariana, No 19, (2008). 